\title{
Clinical Comparison of Optimum and Large Diameter Soft
}

Contact Lenses

3

(1)

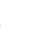

$\begin{array}{ll}\text { AUTHORS: } & \text { James Wolffsohn FCOptom PhD MBA } \\ & \text { Lee Hall BSc PhD FBCLA }^{\text {a,b }} \\ & \text { Graeme Young FCOptom MPhil PhD DCLP }\end{array}$

a Visioncare Research Ltd, Craven House, Arundell Place, West Street, Farnham, GU9 7EN, UK

b Ophthalmic Research Group, Aston University, Aston Triangle, Birmingham, B4 7ET, UK

\section{CORRESPONDENCE: Graeme Young, G.Young@visioncare.co.uk, Visioncare Research Ltd,} Craven House, Arundell Place, West Street, Farnham, GU9 7EN.

\footnotetext{
ACKNOWEDGEMENTS: We thank Chris Hunt for assistance with the statistical analysis and Nathan Greenaway for help in preparation of the manuscript.
} 


\section{ABSTRACT}

3 PURPOSE: To compare the clinical performance of large diameter lenses with optimally fit lenses in 4 the same material and monocurve back surface design.

5 METHOD: In a four-visit, randomised, bilateral, crossover, study, 25 myopic subjects wore optimum 6 diameter lenses (control) and large diameter lenses (test) in random succession for 1 week each. Both 7 study lenses were made of methafilcon $A$ and of an identical design. Trial fittings with Frequency 55 8 (Coopervision) lenses modified with a design algorithm were used to determine the appropriate custom9 made study lenses.

RESULTS: The least squares mean scores $( \pm S E)$ for overall comfort and end-of-day comfort (0-10 scale) were $7.57 \pm 0.33$ vs. $7.42 \pm 0.33(P=0.59)$ and $7.00 \pm 0.31$ vs. $7.27 \pm 0.32(P>0.05)$ for the optimum and large diameter lenses, respectively. There were no significant differences in mean $( \pm S E)$ gradings for limbal hyperaemia ( $1.23 \pm 0.11$ vs. $1.19 \pm 0.11,0-4$ scale, $P=0.60)$ and corneal staining $(1.79 \pm 0.25$ vs. $2.04 \pm 0.25, P=0.39$ ). Conjunctival staining was greater for the optimum lens: $1.80 \pm 0.28$ vs. 0.93 \pm 0.28 ( $0-4$ scale, $P=0.001$ ). With regard to lens fit, the large diameter lenses showed significantly less post-blink movement ( $0.22 \pm 0.01$ vs. $0.16 \pm 0.01 \mathrm{~mm}, \mathrm{P}=0.004)$, and greater total decentration ( 0.15 \pm 0.02 vs. $0.21 \pm 0.02 \mathrm{~mm}, P=0.010$ ). However, there was no significant difference in the key fit variable of tightness on push-up ( $46 \pm 0.69 \%$ vs. $48 \pm 0.69 \%, 0$ - 100 scale, $P=0.12$ ).

DISCUSSION: The findings suggest that larger than optimal soft lenses may be worn without detriment to either comfort or ocular physiology, provided an optimal fit is otherwise maintained. 


\section{INTRODUCTION}

Corneal diameter (CD) varies widely in a typical population, for instance, horizontal $C D$ has been measured by ocular coherence tomography (OCT) to range from 12.1 to $14.4 \mathrm{~mm}$.[1] The importance of the relationship between lens and corneal diameter is clinically accepted and textbooks typically suggest that lenses should overlap the limbus by at least 1-2 $\mathrm{mm}$.[2][3]

Lenses that are too small for a given eye cause irritation due to the edge encroaching onto the cornea. However, the clinical effects of lenses which are too large are uncertain and there has been little previous work in this area.[4] Theoretical calculations suggest that relatively large lenses can cause excess peripheral pressure.[5] Since many soft lens types are only available in a single diameter, it is inevitable that a significant proportion of lenses dispensed are larger than optimum. It would therefore be useful to have a better understanding of the impact of large diameter lenses on comfort and ocular physiology. The purpose of this study was to evaluate the clinical effect of relatively large diameter soft lenses compared with the effects of optimally fit lenses.

\section{METHOD}

This was a randomised, bilateral, unmasked, crossover, study that compared the clinical performance of optimally fit methafilcon A lenses with larger diameter lenses of the same monocurve design and material for 1 week each. The study was undertaken at two investigational sites in the United Kingdom (Aston University, Birmingham; Visioncare Research, Farnham) between January and May 2015.

Twenty-five subjects, aged between 18 and 70 years, were enrolled and dispensed with lenses. Subjects were required to have a spherical contact lens requirement in the range -0.50 to $-6.00 \mathrm{D}$ and astigmatism less than $1.50 \mathrm{D}$ in both eyes. Subjects were excluded if they demonstrated any signs of ocular infection, allergy, disease or corneal irregularity that could interfere with contact lens wear. Subjects were also excluded who had undergone corneal refractive surgery or any anterior segment surgery or had recently worn rigid contact lenses. Neophyte subjects were allowed, although most were existing soft contact lens wearers.

Both lens types were lathecut methafilcon A hydrogel lenses which were ordered following trial fitting with a cast moulded lens of the same material (Frequency ${ }^{\circledR} 55$, CooperVision, Pleasanton, CA, USA). The lathecut lenses were custom manufactured to match the thickness and edge profile of the cast moulded lens (Ultravision CLPL, Leighton Buzzard, UK). The lens used for trial fitting was a single diameter and base curve design (Table 1) and, therefore, in order to select the optimum design for a given eye, an algorithm was used to: i) compensate for non-optimum tightness (i.e. tight or loose), ii) adjust for non-optimal lens diameters (Appendix 1). For a lens fitting to be judged as optimum, it was required to cover the cornea in all directions of gaze, be central to the cornea with around $1.2 \mathrm{~mm}$ of conjunctival overlap, show sufficient post-blink movement with no edge stand-off, and to show optimal tightness by the push-up test.[6][7] The methods for assessing lens fit have previously been described.[7]

Horizontal visible iris diameter was measured with a $0.1 \mathrm{~mm}$ increment graticule using a slit lamp biomicroscope and horizontal corneal diameter with an Anterior Segment Optical Coherence Tomographer (AS-OCT; Visante, Carl-Zeiss, Oberkochen Germany). Corneal topography was also conducted (E300, Medmont, Nunawading, VIC, Australia). 
The large diameter lens was specified as being $1.2 \mathrm{~mm}$ larger in diameter than the optimal lens and $0.6 \mathrm{~mm}$ flatter in base curve so as to give a clinically equivalent fitting (e.g. Optimal lens $=8.6 / 14.2$; Large diameter lens $=9.2$ /15.4).[5] Since the lenses were custom made, the first pair was dispensed at a second visit at which the lens fit and visual performance were assessed and confirmed to be satisfactory.

Subjects were issued with the AOSept (Alcon, Fort Worth, TX, USA) hydrogen peroxide disinfection system. The use of saline for rinsing prior to insertion and rewetting drops was allowed, only if necessary.

A range of clinical variables was assessed at baseline and then reassessed the 1-week follow-up visit (Table 2) with the subjects having worn the lenses for at least 2 hours on those visit days. Slit lamp findings were graded with reference to the CCLRU grading scales.[8] For assessment of corneal staining, a yellow filter was used to enhance the appearance of any staining and this was graded for each of five corneal sectors. Similarly, for conjunctival staining, this was graded for each of four segments.

Lens comfort (insertion, during day and end-of-day) was graded by subjects on a 0-10 scale. Symptoms were monitored with the CLDEQ-8 questionnaire.[9] The CLDEQ-8 results were consolidated to produce a total score on a 0-33 scale. Subjects reported their typical insertion time and, if there was a reduction in comfort, the time that this typically occurred so that their comfortable wearing time could be determined.

Between follow-up visits, subjective comfort was monitored by SMS text messaging. Subjects were contacted four times a day (08:00,12:00,16:00,20:00) on Days 2 and 6 of each lens wear period and asked to grade current lens comfort, also on a 0-10 scale. The SMS messages were pre-scheduled to be sent and received via an internet-based messaging service, FASTSMS (Worcestershire, UK, http://www.fastsms.co.uk/).

The study followed the tenets of the Declaration of Helsinki (2013). The protocol was reviewed by the Aston University Ethics Committee and a favourable opinion was received prior to undertaking the study. All subjects received detailed information about the study and signed an informed consent form before participation.

Statistical Analysis

The statistical analysis was undertaken using SAS software Version 9.4 (SAS Institute, Cary, NC, USA). Four hypotheses were tested, specifically, that the following four variables would be significantly poorer with the large diameter lenses compared with the optimal lenses: overall comfort (at visit), end-of-day comfort, limbal hyperaemia, and conjunctival fluorescein staining. Each of these was tested using mixed linear models. The models included the following fixed effects: lens, order, visit, and site; and the random effect subject nested in site. Non-inferiority was concluded if the lower limit of the 95\% confidence interval of the difference (test-control) was greater than $X$ and superiority if the lower bound was greater than zero $(X=-0.5,-1$ and +0.5 for comfort, limbal hyperaemia and conjunctival staining, respectively). Due to the repeated measures study design, the recommended 15 degrees of freedom could be achieved with at least 16 subjects completing the study.[10] Additional variables were tested for statistically significant differences using the mixed model analysis. 


\section{RESULTS}

The results are summarised in Tables 3 to 6 and the statistical analysis of key variables in Tables 8 to 9.

A total of 25 subjects were enrolled and successfully completed the study. The subjects' average age was 32.9 years (SD: 15.9, range: 18-60) and 60\% (15/25) were female (Table 3). The mean sphere refractive error was $-2.97 \mathrm{D}(\mathrm{SD}: 1.07$, range: $-1.25 \mathrm{D}$ to $-5.50 \mathrm{D}$ ) and mean cylindrical refractive error was $-0.43 \mathrm{D}$ (SD: 0.28 , range: Plano to $-1.00 \mathrm{D}$ ). The mean horizontal visible iris diameter, as measured using a slit lamp graticule, was $11.40 \mathrm{~mm}$ (SD: 0.31 , range 10.8 to 12.0 ) and mean palpebral aperture was 10.12 (SD: 1.31 , range 8.0 to 16.0 ).

The mean horizontal corneal diameter, measured by AS-OCT, was $13.23 \mathrm{~mm}$ (SD: 0.54 , range 12.4 to 14.6) and mean vertical corneal diameter was $12.43 \mathrm{~mm}$ (SD: 0.51 , range 11.2 to 13.5$)$. The mean corneal sagittal heights were $3.06 \mathrm{~mm}$ (SD: 0.24 , range 2.61 to 3.59 ) and $2.75 \mathrm{~mm}$ (SD: 0.21 , range 2.16 to 3.16 ) for the horizontal and vertical meridians, respectively.

\section{Comfort}

None of the assessments of overall comfort showed a significant difference and, therefore, the hypothesis, that subjective comfort would be significantly poorer with large diameter, was not met (Table 4). The least squares (LS) mean 1-week comfort scores were 7.42 and 7.57 (0-10 scale) for the large diameter and control lenses, respectively. The LS mean scores for end-of-day comfort were 7.27 and 7.00 (0-10 scale) for the large diameter and control lenses, respectively.

Overall, the comfort assessments by SMS also showed similar LS mean comfort scores: 7.60 vs. 7.73 (0-10 scale) for the large and optimal diameter lenses, respectively. When analysed by time point, two statistically significant differences were noted. Comfort was significantly better for the optimum diameter lens at the midday assessment on Day 2 ( 8.25 vs. $7.58, P<0.05)$, however, the larger diameter lens was rated significantly higher at the evening assessment on Day 6 ( 7.52 vs. $6.76, P<0.05)$ (Figure 1). However, these findings must be treated with caution as they are based on only a proportion of the subject group; the overall response rate for the SMS assessments was $78.8 \%$, and of those subjects $10.8 \%$ could not make an assessment because they were not wearing lenses at the time.

The mean comfortable wearing times reported at the follow-up visit were 9.7 and 9.4 hours, for the large and optimal diameter lenses, respectively.

\section{Symptoms: CLDEQ-8}

The most frequently reported symptoms from the CLDEQ-8 questionnaire were ocular discomfort and dryness. A greater proportion of subjects reported experiencing frequent or constant discomfort while wearing the large diameter lens than for the optimum diameter lens (12 vs. 5 , Figure 2 ).

A similar proportion of subjects reported frequent or constant dryness with the large diameter lens compared to the optimum diameter lens ( 6 vs. 7 , respectively).

\section{Lens Fit}

The mean base curve and lens diameter dispensed were $8.57 / 14.15 \mathrm{~mm}$ for the optimal lenses and $9.17 / 15.35 \mathrm{~mm}$, for the large diameter lenses (Table 5). The diameter of lens judged as optimum ranged 
from 13.6 to $14.8 \mathrm{~mm}$. All of the lens fittings at dispensing were judged as acceptable by the investigators.

At the follow-up assessments, there were significant differences in lens fit with respect to centration, post-blink movement and overall lens fit acceptance.

Total decentration was calculated as the vector summation of horizontal and vertical centration. There was significantly greater total decentration with the large diameter lens compared to the optimum lens, 0.21 vs. $0.15 \mathrm{~mm}(P=0.01)$. There were also significant differences in vertical decentration and absolute horizontal decentration, -0.03 vs. $+0.03 \mathrm{~mm},(P=0.004)$ and 0.14 vs. $0.07 \mathrm{~mm},(P=0.002)$ respectively, for the large and optimum diameter lenses. As expected, diameter acceptance was assessed as significantly greater for the large diameter lenses: 1.20 vs. $0.01 \mathrm{~mm}(P<0.0001)$.

The large diameter lens showed significantly less post-blink movement than the optimum lens, $0.16 \mathrm{vs}$. $0.22 \mathrm{~mm},(P=0.004)$. There was no significant difference in lens tightness between the two lenses, $48 \%$ vs. $46 \%$ for the large and optimum diameter lenses, respectively $(P=0.12)$.

Despite the optimisation of fit, investigators rated overall fit acceptance significantly poorer for the large diameter lens compared with the optimum diameter lens, 3.48 vs. $3.88,(0-5$ scale, $P=0.0005)$. Six of the 100 lens fittings were judged as unacceptable due to insufficient movement on blink; four were large diameter lenses and two were optimal diameter lenses.

\section{$\underline{\text { Slit Lamp Findings }}$}

The slit lamp findings are summarised in Table 6. There was a significant difference between the optimum and large diameter lenses for conjunctival fluorescein staining; however, there were no significant differences for any of the other slit lamp variables.

The primary hypothesis, that limbal hyperaemia will be significantly greater with large diameter soft lenses compared with optimally fit lenses, was not met: 1.19 vs. 1.23 (0-4 scale) [Least Square Mean Difference (LSMD): $0.0,95 \%$ CL: $(-0.2,0.1)]$. The lower confidence interval is greater than the lower confidence bound. Hence it can be concluded that the large diameter and optimum lenses were equivalent with respect to limbal hyperaemia (Figure 3).

The secondary hypothesis, that corneal staining will be significantly greater with large diameter soft lenses was not met: 2.04 vs. 1.79 (0-4 scale) [LSMD +0.3, 95\% CL: (-1.3, -0.4)] (Figure 3). A similar proportion of eyes showed corneal staining with the large and optimum diameter lenses $(74 \%$ vs. $68 \%$, respectively). Corneal staining type did not exceed $>$ Grade 2 for either lens.

The primary hypothesis, that conjunctival fluorescein staining will be significantly greater with large diameter soft lenses was not met: 0.93 vs. 1.80. (0-4 scale) [LSMD: $-0.9,95 \%$ CL: $(-1.3,-0.4)$ ], $P=0.0006$. Since the upper bound was less than zero but still greater than the lower equivalence margin, conjunctival staining was therefore statistically significantly greater with the optimum lens than the larger diameter lens, although this was not clinically significant (Figure 3, Figure 4).

In addition, a greater proportion of eyes showed conjunctival staining with the optimum lens than with the large diameter lenses (52\% vs. $34 \%$ ). 
Lens Metrology

Centre thickness, peripheral junction thickness and edge thicknesses were measured for a sample of lenses from nine subjects (Table 7). Thicknesses were measured using a Rehder thickness gauge (West Lafayette, IN, USA).

\section{DISCUSSION}

\section{$\underline{\text { Comfort }}$}

There were few differences in comfort ratings between the large and optimum diameter lenses. Interestingly, there was no significant difference in either overall comfort or end-of-day comfort. These are unexpected findings given the increased interaction between the lids and lens edge as a result of the greater surface area of the larger lenses. The fact that there was no difference might, in part, be explained by the similar centre thickness and peripheral thickness for the two lens types. The fact that the lenses were identical material and all fitted to give optimum fit also reduces the risk of one lens type being less comfortable than the other.[4]

Subjects did, however, report more frequent discomfort with the larger diameter lens, although there was no significant difference in the intensity of discomfort. Given that there was no difference in overall comfort, these findings would suggest that subjects experienced more frequent but transitory episodes of lens awareness.

\section{Slit Lamp Findings}

The only difference in ocular physiology was related to conjunctival staining, which was significantly greater for the optimum diameter lens than the large diameter lens. This is a surprising finding, as the pressure of the eyelids acting over a larger surface area might have been expected to produce greater mechanical interaction between the lens and conjunctiva. Two possible explanations for the greater conjunctival staining with the optimal design are: i) increased conjunctival exposure, and ii) greater lens movement.

Some mid-peripheral corneal staining (especially superior epithelial arcuate lesions [SEAL] or pre-SEAL staining), might have been expected with the larger diameter lens, but was not the case. It is likely that, in both instances, such staining may have been avoided by the lower modulus material employed in the manufacture of the study lenses.

A greater degree of limbal hyperaemia might have been expected with the larger lens as a result of greater mechanical interaction coupled with reduced oxygen supply. The fact that this was not the case may have been due to the fact that both lenses were fitted so as to give optimum tightness of fit. In relation to oxygen, although the larger lens covered a larger area of conjunctiva ( $15 \%$ difference between the diameters), the lens thicknesses were similar over the cornea and therefore supplied similar levels of oxygen to the cornea.

\section{Lens Fit}

Post-blink movement was significantly less with the large diameter lenses, even though the larger surface area of the large lens might have been expected to encourage greater movement. However, F:IPAPERSIVCRIAston Diameter/9Feb17 - 6 PAP Aston Diameter 
increased surface area is also likely to increase friction between the lens and ocular surface which would discourage movement. On balance, this finding suggests that the latter effect predominates.

Despite the fact that the larger diameter lenses were optimised for fit, overall lens fit acceptability was still rated significantly poorer than for the optimum diameter lenses. This was partly due to the greater decentration seen with the larger lenses, most likely a result of the greater mass of the lens acting with gravity. Also, the reduced movement with the larger lenses resulted in four fittings being downgraded to unacceptable.

It is possible that differences in lens fit may have been evident if the large diameter lenses had not been optimised with respect to base curve; in other words, if the diameter had been increased without a compensating change to base curve. In particular, greater lens tightness might have been apparent due to the increased sagittal depth of the lens. This might also have resulted in greater peripheral pressure,[5] leading to conjunctival indentation and increased conjunctival staining.

\section{Optimum Design}

To the best of the authors' knowledge, this study was unique in selecting the optimum soft lens parameters to the nearest $0.2 \mathrm{~mm}$ and placing no limits on $\mathrm{BC}$ or diameter. It is notable that this led to the use of a wide range of parameters. The range of optimum diameters was $1.2 \mathrm{~mm}$, however, this was small in comparison with the range of horizontal corneal diameters $(>2.2 \mathrm{~mm})$. Table 7 shows that a large proportion of the optimal lens designs selected were outside of the range of lenses typically offered. Although the present study suggests that the larger than optimal lens diameters should not be a concern, other compromises of lens fit may be problematic. Small lens diameters are known to cause discomfort.[11] In addition, a previous study has shown that relatively loose or tight fittings can lead to increased corneal staining and conjunctival hyperaemia.[12]

\section{Limitations of the Study}

Although objective ways of assessing soft lens fit have been developed, subjective evaluation is almost as repeatable, though the range of values is generally reduced.[13] Since there are currently no reliable objective methods for selecting an optimal soft lens design for a given eye, a possible source of error is that this relied on the judgement of the investigator. However, the lens fit assessments with the final lenses suggest that this was relatively successful. All of the final optimal lenses were judged on-eye to be within $0.3 \mathrm{~mm}$ of optimal.

The larger lenses were optimised for tightness of fit whereas theoretical data suggest that, in a typical population, large diameter lenses tend to be tighter than optimum.[5] It is possible, therefore, that the results would be different when looking at large lenses coupled with a relatively tight fit.

In conclusion, this study has shown that larger than optimal soft lenses may be worn without detriment to comfort or ocular physiology provided an optimal fit is otherwise maintained. 


\section{REFERENCES}

[1] L. Hall, C. Hunt, G. Young, J. Wolffsohn, Factors affecting corneoscleral topography, Invest. Ophthalmol. Vis. Opt. 54 (2013) 3691-3701.

[2] G. Young, Soft Contact Lens Design and Fitting, in: N. Efron (Ed.), Contact Lens Practice, second ed., Butterworth-Heinemann, Oxford, 2000, pp. 109-118.

[3] L. Jones, K. Dumbleton, Soft Contact Lens Fitting, in: A. Phillips, L. Speedwell (Eds.), Contact Lenses, fifth ed., Butterworth- Heinemann/Elsevier, Edinburgh, 2007, pp. 223-240.

[4] L. Jones, N. Brennan, J. Gonzalez-Meijome, J. Lally, C. Maldonado-Codina, T. Schmidt, L. Subbaraman, G. Young, J. Nichols, The international workshop on contact lens discomfort: report of the contact lens materials, design \& care subcommittee, Invest. Ophthalmol. Vis. Sci. 54 (11) (2013) TFOS37-TFOS70.

[5] G. Young, A. Sulley, K. Osborn, L. Hall, J. Wolffsohn, The inter-relationship of soft contact lens diameter, base curve radius, and fit, Optom. Vis. Sci. In press.

[6] D.K. Martin, J. Boulos, J. Gan, et al., A unifying parameter to describe the clinical mechanics of hydrogel contact lenses, Optom. Vis. Sci. 66 (1989) 87-91.

[7] G. Young, Evaluation of soft contact lens fitting characteristics, Optom. Vis. Sci. 73 (1996) 247254.

[8] Terry R L, Schnider CM, Holden BA, Cornish R, Grant T, Sweeney D, La Hood D, Back A. CCLRU standards for success of daily and extended wear contact lenses. Optom Vis Sci 1993; 70:234-43.

[9] R.L. Chalmers, C.G. Begley, K. Moody, S.B. Hickson-Curran, Contact lens dry eye questionnaire-8 (CLDEQ-8) and opinion of contact lens performance, Optom. Vis. Sci. 89 (2012) 1435-1442.

[10] R.A. Armstrong, F. Eperjesi, B. Gilmartin, The application of analysis of variance (ANOVA) to different experimental designs in optometry, Ophthal. Physiol. Opt. 22 (2002) 248-256.

[11] N.A. McNamara, K.A. Polse, R.J. Brand, A.D. Graham, J.S. Chan, C.D. McKenney, Tear mixing under a soft contact lens: effects of lens diameter, Am. J. Ophthalmol. 127 (1999) 659-665.

[12] G. Young, S. Coleman, Poorly fitting soft lenses adversely affect ocular integrity, CLAO J 27 (2001) 67-74.

[13] L. Belda-Salmeron, T. Drew, L. Hall, J.S. Wolffsohn, Objective analysis of lens fit, Cont. Lens Anterior Eye 38 (2015) 163-167. 
Table 1: Lens Details

\begin{tabular}{|c|c|c|c|}
\hline & Trial Lenses & Controls & Test \\
\hline Manufacturer & CooperVision & \multicolumn{2}{|c|}{ Ultravision } \\
\hline Material & methafilcon A & \multicolumn{2}{|c|}{ methafilcon A } \\
\hline Water content (\%) & 55 & \multicolumn{2}{|c|}{55} \\
\hline Design & Frequency $^{\circledR} 55$ & \multicolumn{2}{|c|}{$\begin{array}{l}\text { Custom manufactured, monocurve back } \\
\text { surface, tricurve front surface }\end{array}$} \\
\hline Base curve (mm) & 8.60 & \multicolumn{2}{|c|}{8.20 to 9.00 in 0.2 steps } \\
\hline Diameter (mm) & 14.2 & \multicolumn{2}{|c|}{13.5 to 16.0 in 0.1 steps } \\
\hline Fitting & - & Optimal & $\begin{array}{c}\text { Optimal diameter }+ \\
1.2 \mathrm{~mm} \text {; optimal } \\
\text { base curve }+0.6 \mathrm{~mm}\end{array}$ \\
\hline Sphere powers (D) & -0.50 to -6.00 & \multicolumn{2}{|c|}{-0.50 to -6.00} \\
\hline
\end{tabular}

3 Frequency ${ }^{\circledR} 55$ lenses were used as trial lenses to determine the optimum diameter for a given subject 4 by using photography to determine the limbal overlap. 
Table 2: Summary of Clinical Assessments

Comfort \& Symptoms

Comfort $(0-10$, where $10=$ cannot be felt $)$

CLDEQ-8 (0-33 scale, $0=$ no problems)

Lens Fit

- Lens centration $(\mathrm{mm}$, -ve value $=$ inferior or temporal)

- Corneal coverage $(\mathrm{Y} / \mathrm{N})$

- Post blink movement (mm)

- Primary-gaze lag (mm)

- Tightness on push-up $(0-100,50=$ optimal, $<50$ loose, $>50$ tight $)$

- Overall fit acceptance (0-5, Grade 3-5 = acceptable)

Slit lamp Examination

- Limbal hyperaemia (0-4, 0.1 steps)

- Bulbar hyperaemia (0-4, 0.1 steps)

- Palpebral hyperaemia (0-4, 0.1 steps)

- Palpebral roughness (0-4, 0.1 steps)

- Corneal staining (0-4 in 5 sectors, i.e. 0-20)

- Conjunctival fluorescein staining (0-4 in 4 segments, i.e. 0-16)

- Conjunctival indentation (0-4)

- Other findings (0-4). 

OCT).

\begin{tabular}{|c|c|c|c|}
\hline Variable & & & \\
\hline No. of Subjects / Eyes & & $25 / 50$ & \\
\hline Age (years) & $\begin{array}{l}\text { Mean (SD) } \\
\text { Range }\end{array}$ & $\begin{array}{c}32.9(15.9) \\
18-60\end{array}$ & \\
\hline Sex & Male: Female & $10: 15$ & \\
\hline Spectacle sphere (D) & $\begin{array}{l}\text { Mean (SD) } \\
\text { Range }\end{array}$ & $\begin{array}{l}-2.97(1.07) \\
-5.50 \text { to }-1.25\end{array}$ & \\
\hline Spectacle cylinder (D) & $\begin{array}{l}\text { Mean (SD) } \\
\text { Range }\end{array}$ & $\begin{array}{l}-0.43(0.28) \\
-1.0 \text { to } 0.00\end{array}$ & \\
\hline Cylinder axis ( $\mathrm{N}$ eyes $(\%))$ & $\begin{array}{l}\text { WTR } \\
\text { ATR } \\
\text { Oblique }\end{array}$ & $\begin{array}{c}22(44 \%) \\
14(28 \%) \\
14(28 \%)\end{array}$ & \\
\hline $\begin{array}{l}\text { Palpebral Aperture } \\
(\mathrm{mm})\end{array}$ & $\begin{array}{l}\text { Mean (SD) } \\
\text { Range }\end{array}$ & $\begin{array}{c}\text { Horizontal } \\
-\end{array}$ & $\begin{array}{c}\text { Vertical } \\
10.12(1.31) \\
8.0-16.0\end{array}$ \\
\hline $\begin{array}{l}\text { Horizontal Visible } \\
\text { Iris Diameter }(\mathrm{mm})\end{array}$ & $\begin{array}{l}\text { Mean (SD) } \\
\text { Range }\end{array}$ & $\begin{array}{c}11.40(0.31) \\
10.8-12.0\end{array}$ & - \\
\hline $\begin{array}{l}\text { Corneal Apical Radius } \\
(\mathrm{mm})\end{array}$ & $\begin{array}{l}\text { Mean (SD) } \\
\text { Range }\end{array}$ & $\begin{array}{l}7.77(0.20) \\
7.40-8.15\end{array}$ & $\begin{array}{l}7.76(0.20) \\
7.37-8.14\end{array}$ \\
\hline Corneal Shape Factor & $\begin{array}{l}\text { Mean (SD) } \\
\text { Range }\end{array}$ & $\begin{array}{l}0.46(0.13) \\
0.09-0.65\end{array}$ & $\begin{array}{c}0.76(0.12) \\
0.40-1.00\end{array}$ \\
\hline $\begin{array}{l}\text { Corneal Diameter } \\
(\mathrm{mm})\end{array}$ & $\begin{array}{l}\text { Mean (SD) } \\
\text { Range }\end{array}$ & $\begin{array}{l}13.23(0.54) \\
12.35-14.59\end{array}$ & $\begin{array}{l}12.43(0.51) \\
11.20-13.45\end{array}$ \\
\hline $\begin{array}{l}\text { Corneal Sagittal } \\
\text { Height }(\mathrm{mm})\end{array}$ & $\begin{array}{l}\text { Mean (SD) } \\
\text { Range }\end{array}$ & $\begin{array}{l}3.06(0.25) \\
2.61-3.59\end{array}$ & $\begin{array}{l}2.75(0.21) \\
2.16-3.16\end{array}$ \\
\hline $\begin{array}{l}\text { Corneo-scleral } \\
\text { Junction Angle }\left({ }^{\circ}\right)\end{array}$ & $\begin{array}{l}\text { Mean (SD) } \\
\text { Range }\end{array}$ & $\begin{array}{c}172.0(2.5) \\
166-177\end{array}$ & $\begin{array}{c}177.7(2.2) \\
172-183\end{array}$ \\
\hline $\begin{array}{l}\text { Corneo-scleral } \\
\text { Junction Angle }\left({ }^{\circ}\right)\end{array}$ & $\begin{array}{l}\text { Mean (SD) } \\
\text { Range }\end{array}$ & $\begin{array}{c}177.4(1.6) \\
174-180\end{array}$ & $\begin{array}{c}177.7(1.8) \\
173-184\end{array}$ \\
\hline
\end{tabular}


VISIONCARE RESEARCH

Table 4: Summary of Subjective Assessments and Wearing Times.

\begin{tabular}{|c|c|c|c|c|c|c|c|}
\hline \multirow[b]{2}{*}{ Variable } & & \multirow[b]{2}{*}{$\begin{array}{l}\text { Frequency } \\
\quad 55\end{array}$} & \multicolumn{2}{|c|}{ Dispensing } & \multicolumn{2}{|c|}{ Follow-up } & \multirow[b]{2}{*}{ P-values } \\
\hline & & & $\begin{array}{c}\text { Large } \\
\text { Diameter }\end{array}$ & $\begin{array}{l}\text { Optimum } \\
\text { Diameter }\end{array}$ & $\begin{array}{l}\text { Large } \\
\text { Diameter }\end{array}$ & $\begin{array}{l}\text { Optimum } \\
\text { Diameter }\end{array}$ & \\
\hline No. of Subjects & & 25 & 25 & 25 & 25 & 25 & \\
\hline $\begin{array}{l}\text { Overall Comfort } \\
(0-10)\end{array}$ & $\begin{array}{l}\text { Mean (SD) } \\
\text { Range }\end{array}$ & $\begin{array}{c}8.86(1.1) \\
6-10\end{array}$ & $\begin{array}{c}9.00(1.0) \\
7-10\end{array}$ & $\begin{array}{c}8.95(0.9) \\
7-10\end{array}$ & $\begin{array}{c}7.31(1.6) \\
5-10\end{array}$ & $\begin{array}{c}7.46(1.8) \\
3-10\end{array}$ & 0.59 \\
\hline $\begin{array}{l}\text { End-of-day } \\
\text { Comfort } \\
(0-10)\end{array}$ & $\begin{array}{l}\text { Mean (SD) } \\
\text { Range }\end{array}$ & - & - & - & $\begin{array}{c}7.27(3.2) \\
2-10\end{array}$ & $\begin{array}{c}7.00(3.1) \\
4-10\end{array}$ & 0.55 \\
\hline $\begin{array}{l}\text { CLDEQ-8 } \\
(0-33)\end{array}$ & $\begin{array}{l}\text { Mean (SD) } \\
\text { Range }\end{array}$ & - & - & & $\begin{array}{c}9.16(6.1) \\
2-25\end{array}$ & $\begin{array}{c}8.64(5.5) \\
2-23\end{array}$ & 0.65 \\
\hline $\begin{array}{l}\text { Average WT } \\
\text { (hrs) }\end{array}$ & $\begin{array}{l}\text { Mean (SD) } \\
\text { Range }\end{array}$ & - & - & - & $\begin{array}{c}11.9(2.4) \\
8-18\end{array}$ & $\begin{array}{c}11.5(2.6) \\
6-18\end{array}$ & - \\
\hline $\begin{array}{l}\text { Comfortable WT } \\
\text { (hrs) }\end{array}$ & $\begin{array}{l}\text { Mean (SD) } \\
\text { Range }\end{array}$ & - & - & - & $\begin{array}{l}9.5(3.4) \\
3-17\end{array}$ & $\begin{array}{l}9.1(3.7) \\
3-18\end{array}$ & 0.67 \\
\hline
\end{tabular}


$1 \quad$ Table 5: $\quad$ Summary of Lens Fit at Dispensing and Follow-up.

\begin{tabular}{|c|c|c|c|c|c|c|c|}
\hline \multirow[b]{2}{*}{ Variable } & & \multirow[b]{2}{*}{$\begin{array}{l}\text { Frequency } \\
55\end{array}$} & \multicolumn{2}{|c|}{ Dispensing } & \multicolumn{3}{|c|}{ Follow-up } \\
\hline & & & $\begin{array}{l}\text { Large } \\
\text { Diameter }\end{array}$ & $\begin{array}{l}\text { Optimum } \\
\text { Diameter }\end{array}$ & $\begin{array}{l}\text { Large } \\
\text { Diameter }\end{array}$ & $\begin{array}{l}\text { Optimum } \\
\text { Diameter }\end{array}$ & P-value \\
\hline \multicolumn{2}{|l|}{ No. of Eyes } & 50 & 50 & 50 & 50 & \multicolumn{2}{|l|}{50} \\
\hline \multirow{2}{*}{$\begin{array}{l}\text { Tightness on } \\
\text { Push-up (\%) }\end{array}$} & Mean (SD) & $44.8(6.0)$ & $48.6(5.6)$ & $48.7(5.0)$ & $47.3(4.6)$ & $45.9(4.2)$ & \multirow[t]{2}{*}{0.12} \\
\hline & Range & $38-$ & $42-$ & $43-$ & $40-$ & $35-$ & \\
\hline \multirow{2}{*}{$\begin{array}{l}\text { Post-blink } \\
\text { Movement (mm) }\end{array}$} & Mean (SD) & $0.22(0.1)$ & $0.17(0.1)$ & $0.18(0.1)$ & $0.17(0.1)$ & $0.23(0.1)$ & \multirow[t]{2}{*}{0.0038} \\
\hline & Range & $0.1-0.6$ & $0.1-0.3$ & $0.1-0.4$ & $0.0-0.4$ & $0.0-0.5$ & \\
\hline \multirow{2}{*}{$\begin{array}{l}\text { Primary-gaze } \\
\text { Lag }(\mathrm{mm})\end{array}$} & Mean (SD) & $0.26(0.1)$ & $0.29(0.2)$ & $0.27(0.1)$ & $0.32(0.3)$ & $0.32(0.1)$ & \multirow[t]{2}{*}{ - } \\
\hline & Range & $0.1-0.6$ & $0.1-0.6$ & $0.0-0.6$ & $0.0-1.5$ & $0.0-0.7$ & \\
\hline \multirow{2}{*}{$\begin{array}{l}\text { Total } \\
\text { Decentration }(\mathrm{mm})\end{array}$} & Mean (SD) & $0.21(0.1)$ & $0.31(0.2)$ & $0.24(0.1)$ & $0.20(0.2)$ & $0.14(0.1)$ & \multirow[t]{2}{*}{0.010} \\
\hline & Range & $0.0-0.6$ & $0.1-0.8$ & $0.1-0.5$ & $0.0-0.5$ & $0.0-0.3$ & \\
\hline \multirow{2}{*}{$\begin{array}{l}\text { Horizontal } \\
\text { Decentration (mm) }\end{array}$} & Mean (SD) & $-0.08(0.1)$ & $-0.11(0.2)$ & $-0.06(0.2)$ & $-0.06(0.2)$ & $-0.04(0.1)$ & \multirow[t]{2}{*}{0.45} \\
\hline & Range & -0.3 to 0.3 & -0.6 to 0.3 & -0.3 to 0.3 & -0.5 to 0.3 & -0.3 to 0.3 & \\
\hline \multirow{2}{*}{$\begin{array}{l}\text { Vertical } \\
\text { Decentration (mm) }\end{array}$} & Mean (SD) & $0.04(0.2)$ & $-0.05(0.3)$ & $-0.05(0.2)$ & $-0.03(0.2)$ & $0.03(0.1)$ & \multirow[t]{2}{*}{0.0044} \\
\hline & Range & -0.3 to 0.6 & -0.6 to 0.4 & -0.5 to 0.3 & -0.5 to 0.4 & -0.3 to 0.3 & \\
\hline \multirow{2}{*}{$\begin{array}{l}\text { Corneal Coverage } \\
\text { (n eyes }(\%))\end{array}$} & Yes & $50(100 \%)$ & $20(100 \%)$ & $20(100 \%)$ & $50(100 \%)$ & \multirow{2}{*}{$\begin{array}{c}50(100 \%) \\
0(0 \%)\end{array}$} & \\
\hline & No & $0(0 \%)$ & $0(0 \%)$ & $0(0 \%)$ & $0(0 \%)$ & & \\
\hline \multirow{2}{*}{$\begin{array}{l}\text { Diameter } \\
\text { Acceptance }(\mathrm{mm})\end{array}$} & Mean (SD) & $-0.01(0.27)$ & $1.18(0.11)$ & $0.01(0.07)$ & $1.21(0.12)$ & $0.01(0.10)$ & \multirow{2}{*}{$<0.0001$} \\
\hline & Range & -0.6 to 0.7 & 0.9 to 1.4 & -0.1 to 0.2 & 1.0 to 1.5 & -0.2 to 0.3 & \\
\hline \multirow{2}{*}{$\begin{array}{l}\text { Overall Fit } \\
\text { Acceptance (0-5) }\end{array}$} & Mean (SD) & $3.45(0.42)$ & $3.55(0.43)$ & $3.85(0.56)$ & $3.53(0.61)$ & $3.93(0.56)$ & \multirow{2}{*}{0.0005} \\
\hline & Range & $3.0-4.5$ & $3-4$ & $3-5$ & $2-4.5$ & $2-5$ & \\
\hline \multirow{2}{*}{$\begin{array}{l}\text { Fitting Success } \\
\text { (n eyes(\%)) }\end{array}$} & Yes & $50(100 \%)$ & $20(100 \%)$ & $20(100 \%)$ & $46(92 \%)$ & \multirow{2}{*}{$\begin{array}{l}48(96 \%) \\
2(4 \%)^{*}\end{array}$} & \\
\hline & No & $0(0 \%)$ & $0(0 \%)$ & $0(0 \%)$ & $4(8 \%)^{*}$ & & \\
\hline
\end{tabular}

* Insufficient movement on blink 
Table 6: Summary of Slit Lamp Findings.

\begin{tabular}{|c|c|c|c|c|c|}
\hline Variable & & Baseline & $\begin{array}{l}\text { Large } \\
\text { Diameter }\end{array}$ & $\begin{array}{l}\text { Optimum } \\
\text { Diameter }\end{array}$ & $\begin{array}{c}P \text { - } \\
\text { values }\end{array}$ \\
\hline No. of Eyes & & 50 & 50 & 50 & \\
\hline \multirow{2}{*}{$\begin{array}{l}\text { Limbal } \\
\text { Hyperaemia (0-4) }\end{array}$} & Mean (SD) & $1.04(0.51)$ & $1.18(0.53)$ & $1.23(0.52)$ & \multirow[t]{2}{*}{0.60} \\
\hline & Min & $0-2.4$ & $0.1-2.2$ & $0.2-2.3$ & \\
\hline Bulbar & Mean (SD) & $1.22(0.43)$ & $1.30(0.57)$ & $1.37(0.60)$ & \multirow[t]{2}{*}{0.39} \\
\hline Hyperaemia $(0-4)$ & $\begin{array}{l}\text { Range } \\
\text { Range }\end{array}$ & $0.4-2.5$ & $0.3-2.8$ & $0.2-2.7$ & \\
\hline Upper Palpebral & Mean (SD) & $1.16(0.37)$ & $1.29(0.53)$ & $1.30(0.40)$ & \multirow[t]{2}{*}{ - } \\
\hline Hyperaemia $(0-4)$ & Range & $0.5-2.4$ & $0-2.4$ & $0.6-2.5$ & \\
\hline Upper Palpebral & Mean (SD) & $1.00(0.34)$ & $0.83(0.38)$ & $1.02(0.40)$ & \multirow[t]{2}{*}{ - } \\
\hline Roughness (0-4) & Range & $0.4-2.5$ & $0.3-1.8$ & $0.3-2.5$ & \\
\hline Lower Palpebral & Mean (SD) & $1.17(0.43)$ & $1.34(0.59)$ & $1.34(0.57)$ & \multirow[t]{2}{*}{ - } \\
\hline Hyperaemia $(0-4)$ & Range & $0.4-2.4$ & $0.4-2.6$ & $0.2-2.5$ & \\
\hline Lower Palpebral & Mean (SD) & $1.28(0.56)$ & $1.20(0.49)$ & $1.21(0.51)$ & \multirow[t]{2}{*}{ - } \\
\hline Roughness (0-4) & Range & $0.2-2.8$ & $0.3-2.3$ & $0.5-2.6$ & \\
\hline Corneal Staining & Mean (SD) & $0.62(1.10)$ & 1.94 (1.75) & $1.66(1.66)$ & \multirow[t]{2}{*}{-} \\
\hline $\begin{array}{l}\text { Type - Total } \\
(0-20)\end{array}$ & Range & $0-4$ & $0-7$ & $0-7$ & \\
\hline Conjunctival & Mean (SD) & $0.84(1.81)$ & $0.76(1.41)$ & $1.62(2.11)$ & \multirow{2}{*}{0.0006} \\
\hline $\begin{array}{l}\text { Staining - Total } \\
(0-16)\end{array}$ & Range & $0-7$ & $0-6$ & $0-8$ & \\
\hline
\end{tabular}


VISIONCARE RESEARCH

Table 7: Summary of Study Contact Lens Parameters.

\begin{tabular}{|c|c|c|c|}
\hline & & $\begin{array}{l}\text { Large } \\
\text { Diameter }\end{array}$ & $\begin{array}{l}\text { Optimum } \\
\text { Diameter }\end{array}$ \\
\hline No. of Eyes & & 50 & 50 \\
\hline \multirow[t]{2}{*}{ Base Curve (mm) } & Mean (SD) & $9.17(0.19)$ & $8.57(0.19)$ \\
\hline & Range & $8.70-9.70$ & $8.10-9.10$ \\
\hline \multirow[t]{2}{*}{ Diameter (mm) } & Mean (SD) & $15.35(0.29)$ & $14.15(0.29)$ \\
\hline & Range & $14.8-16.0$ & $13.6-14.8$ \\
\hline \multirow[t]{2}{*}{ Back Vertex Power (D) } & Mean (SD) & $-3.04(1.02)$ & $-3.04(1.02)$ \\
\hline & Range & -1.25 to -5.25 & -1.25 to -5.25 \\
\hline Centre Thickness* $(\mu \mathrm{m})$ & Mean (SD) & $93( \pm 17)$ & $92( \pm 14)$ \\
\hline $\begin{array}{l}\text { Peripheral junction } \\
\text { thickness }{ }^{*}(\mu \mathrm{m})\end{array}$ & Mean (SD) & 164 (SD: \pm 14$)$ & 157 (SD: \pm 10$)$ \\
\hline Edge thickness ${ }^{*}(\mu \mathrm{m})$ & Mean (SD) & 150 (SD: \pm 17$)$ & 142 (SD: \pm 15$)$ \\
\hline
\end{tabular}

* Lens thickness measurements taken from nine pairs optimum and large diameter lenses using Rehder gauge $(n=36)$ 
Table 8: Tests of Fixed Effects from the Analysis of Primary Variables.

\begin{tabular}{|c|c|c|c|c|c|}
\hline Variable & Model Term & $\begin{array}{l}\text { Numerator } \\
\text { Degrees of } \\
\text { Freedom }\end{array}$ & $\begin{array}{l}\text { Denominator } \\
\text { Degrees of } \\
\text { Freedom }\end{array}$ & F-Value & P-Value \\
\hline \multirow[t]{4}{*}{ Comfort } & Lens Type & 1 & 23.0 & 0.29 & 0.5931 \\
\hline & Lens Order & 1 & 22.0 & 0.75 & 0.3962 \\
\hline & Pair & 1 & 23.0 & 0.11 & 0.7379 \\
\hline & Site & 1 & 22.0 & 2.82 & 0.1073 \\
\hline \multirow[t]{10}{*}{ Comfort (SMS) } & Lens Type & 1 & 242.8 & 1.07 & 0.3030 \\
\hline & Day & 1 & 242.5 & 0.24 & 0.6223 \\
\hline & Time & 3 & 242.0 & 10.08 & $<.0001$ \\
\hline & Lens Order & 1 & 21.1 & 0.02 & 0.8783 \\
\hline & Pair & 1 & 242.7 & 0.92 & 0.3384 \\
\hline & Day x Type & 1 & 241.8 & 1.72 & 0.1913 \\
\hline & Type $x$ Time & 3 & 242.0 & 2.26 & 0.0823 \\
\hline & Day x Time & 3 & 241.7 & 0.52 & 0.6716 \\
\hline & Day x Type x Time & 3 & 242.1 & 1.09 & 0.3550 \\
\hline & Site & 1 & 21.0 & 2.99 & 0.0985 \\
\hline \multirow[t]{4}{*}{ Limbal Hyperaemia } & Lens Type & 1 & 23.0 & 0.29 & 0.5971 \\
\hline & Lens Order & 1 & 22.0 & 1.27 & 0.2724 \\
\hline & Pair & 1 & 23.0 & 0.52 & 0.4762 \\
\hline & Site & 1 & 22.0 & 0.00 & 0.9444 \\
\hline \multirow[t]{4}{*}{ Conjunctival Staining } & Lens Type & 1 & 23.0 & 15.98 & 0.0006 \\
\hline & Lens Order & 1 & 22.0 & 0.34 & 0.5651 \\
\hline & Pair & 1 & 23.0 & 0.98 & 0.3333 \\
\hline & Site & 1 & 22.0 & 10.66 & 0.0035 \\
\hline
\end{tabular}


Table 9: Least Square Mean Differences Estimates and 95\% Confidence Intervals for Primary Variables at the 1-Week Follow-Up Visit.

\begin{tabular}{|llccccc|}
\hline Variable & Difference & $\begin{array}{c}\text { LS Mean } \\
\text { Difference }\end{array}$ & Std. Err & 95\% CL & $\begin{array}{c}\text { Non- } \\
\text { Inferiority } \\
\text { Met? }\end{array}$ & $\begin{array}{c}\text { Superiority } \\
\text { Met? }\end{array}$ \\
\hline Comfort & Test-Control & -0.2 & 0.28 & -0.7 to 0.4 & No & No \\
SMS comfort - overall & Test-Control & -0.13 & 0.12 & -0.4 to 0.1 & Yes & No \\
Limbal Hyperaemia & Test-Control & -0.0 & 0.09 & -0.2 to 0.1 & Yes & No \\
Conjunctival Staining & Test-Control & -0.9 & 0.22 & -1.3 to -0.4 & Yes & Yes \\
\hline
\end{tabular}

4 LS-Means: least-square means, Std. Err: standard error, CL: confidence limits

5 Non-inferiority is established if the upper confidence limit is less than +0.5 .

6 Superiority is established if the upper confidence limit is less than 0. 
Figure 1

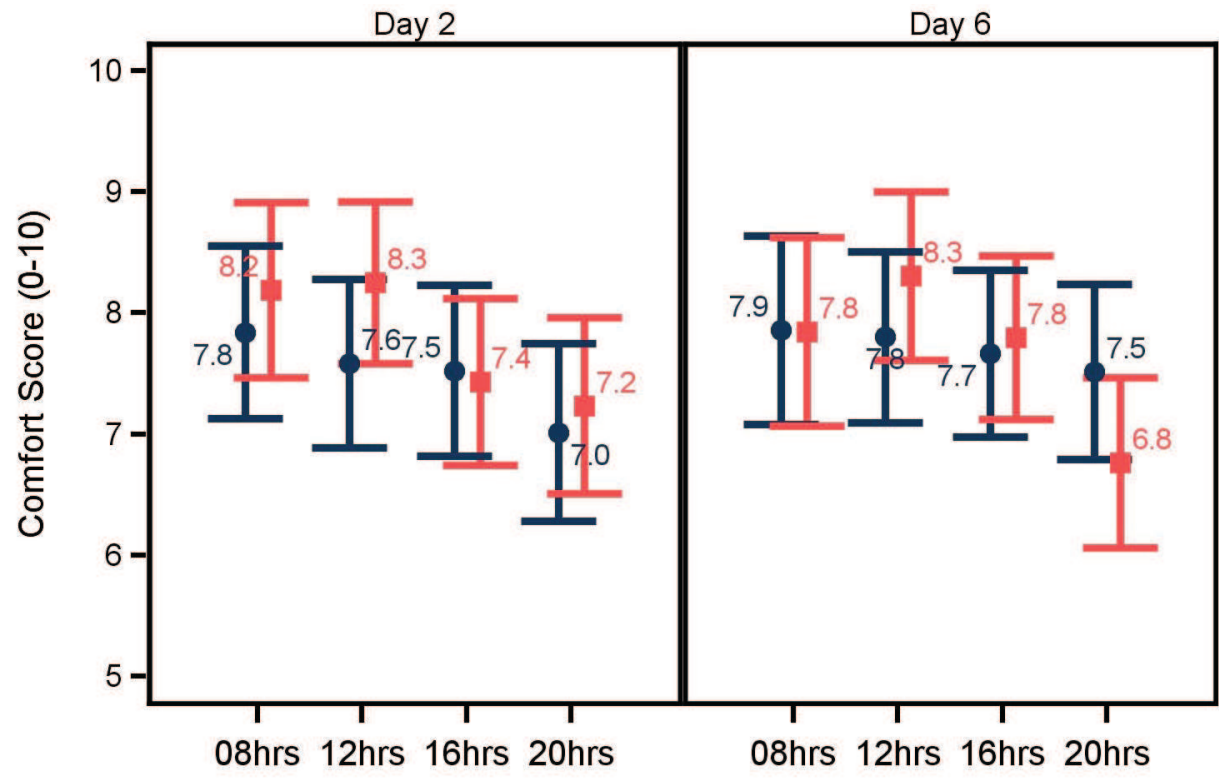

Figure 2

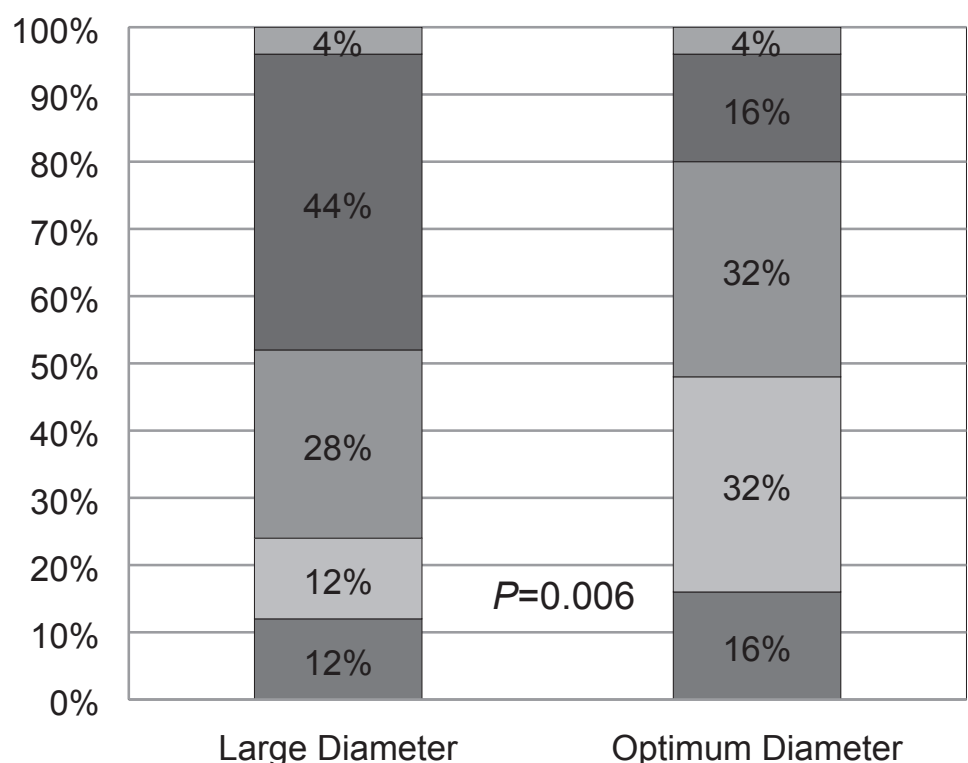

$\square$ Constantly

$\square$ Frequently

$\square$ Sometimes

$\square$ Rarely

$\square$ Never 
Figure 3

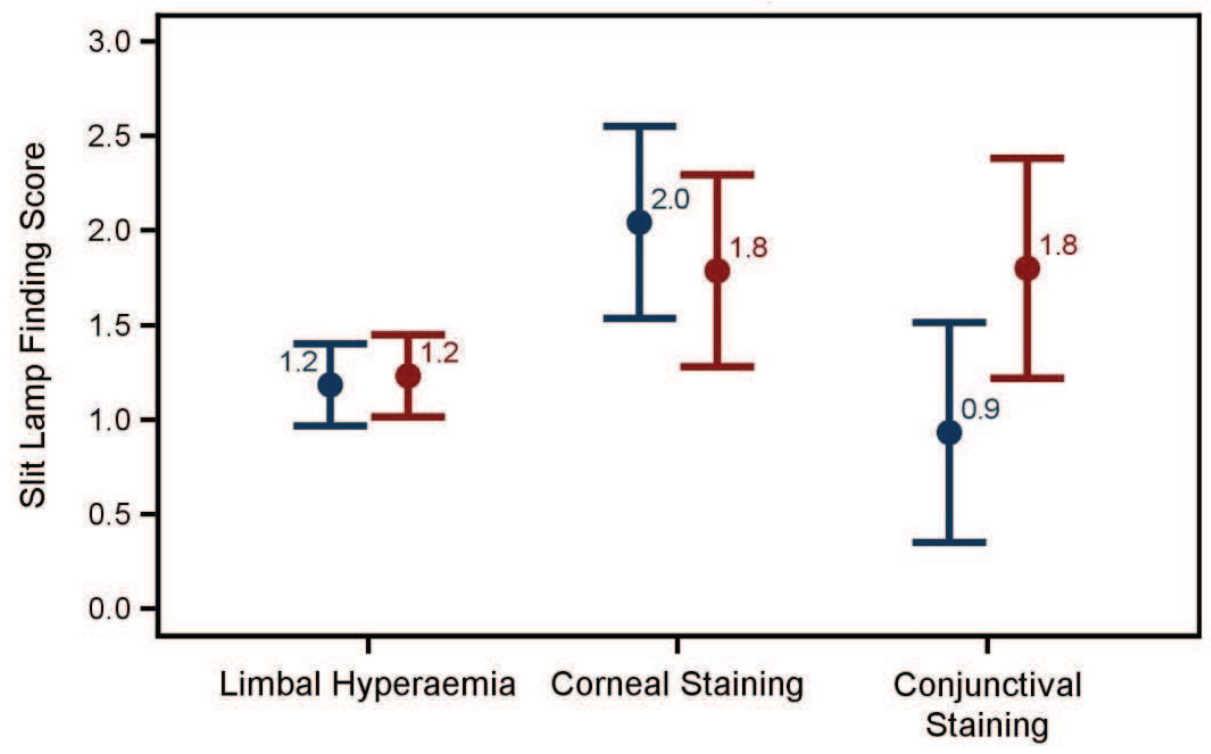

Type Large Optimum

2

4

Figure 4

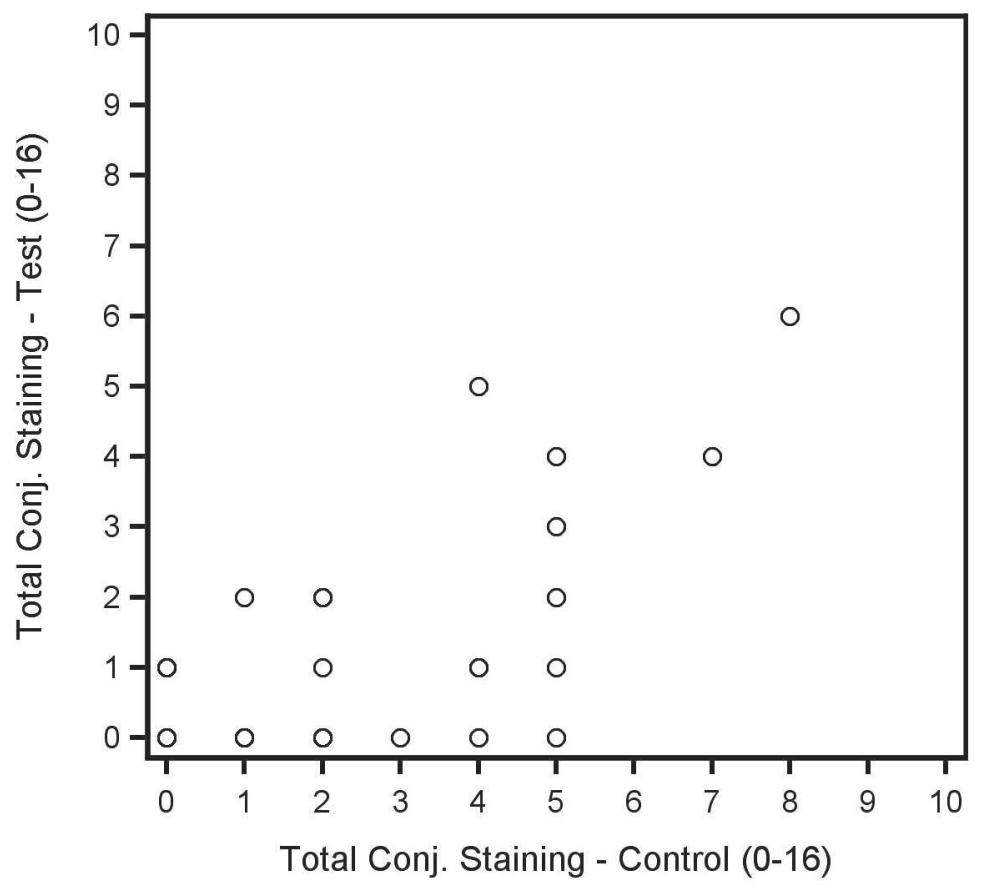


Figure 5

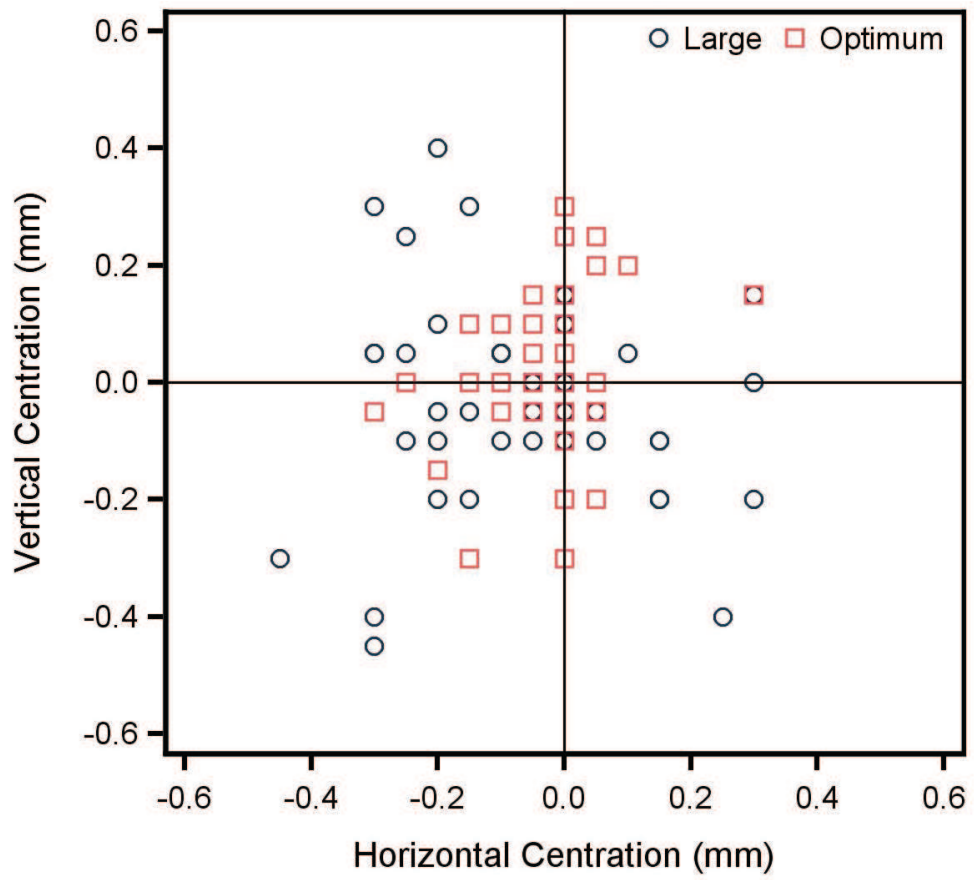

Figure 6

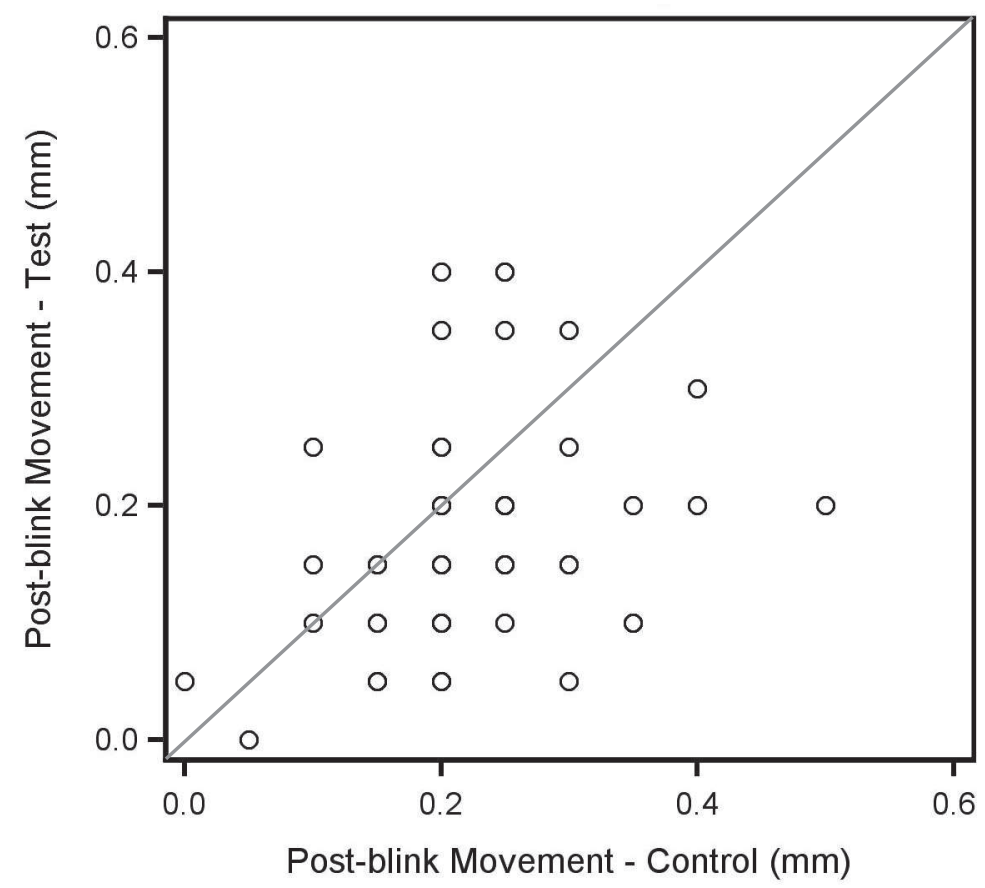

4
5 
1 Legends for Figures:

2 Fig. 1: Least square mean estimates for SMS comfort by day and time (and 95\% confidence 3 intervals)

4 Fig. 2: Frequency of Eye Discomfort from CLDEQ-8 responses

5 Fig. 3: Least square mean estimates for slit lamp findings at 1-week follow-up visit (and 95\% $6 \quad$ confidence intervals)

$7 \quad$ Fig. 4: Scatter plot of conjunctival staining at 1-week follow-up visit

8 Fig. 5: Scatter plot of lens decentration 1-week follow-up visit

9 Fig. 6: Scatter plot of subjective lens post-blink movement 1-week follow-up visit 10 


\section{LENS SELECTION GUIDE}

Guide for selection of optimum lens parameters (BC/Diameter) based on Frequency ${ }^{\circledR} 55$ trial lens

\begin{tabular}{|c|c|c|c|c|}
\hline \multicolumn{2}{|c|}{$\begin{array}{l}\text { Diameter Acceptance } \\
(\mathrm{mm}) *\end{array}$} & Loose & Optimum Fit & Tight \\
\hline \multirow{5}{*}{ 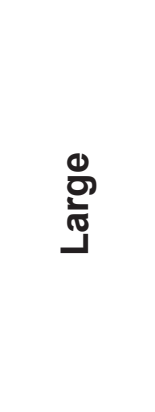 } & +1.0 & - & 8.1 / 13.2 & 8.5 / 13.4 \\
\hline & +0.8 & - & 8.2 / 13.4 & 8.6 / 13.6 \\
\hline & +0.6 & - & 8.3 / 13.6 & $8.7 / 13.8$ \\
\hline & +0.4 & 8.0 / 13.6 & 8.4 / 13.8 & 8.8 / 14.0 \\
\hline & +0.2 & $8.1 / 13.8$ & 8.5 / 14.0 & 8.9 / 14.2 \\
\hline Optimum & 0.0 & 8.2 / 14.0 & 8.6 / 14.2 & 9.0 / 14.4 \\
\hline \multirow{5}{*}{$\begin{array}{c}\overline{\overline{0}} \\
\overline{\mathscr{D}} \\
\overline{\boldsymbol{D}}\end{array}$} & -0.2 & 8.3 / 14.2 & 8.7 / 14.4 & $9.1 / 14.6$ \\
\hline & -0.4 & $8.4 / 14.4$ & $8.8 / 14.6$ & $9.2 / 14.8$ \\
\hline & -0.6 & $8.5 / 14.6$ & 8.9 / 14.8 & - \\
\hline & -0.8 & $8.6 / 14.8$ & $9.0 / 15.0$ & - \\
\hline & -1.0 & 8.7 / 15.0 & $9.1 / 15.2$ & - \\
\hline
\end{tabular}

* +ve indicates larger than optimum for given cornea.

For the Large diameter lens, add $1.2 \mathrm{~mm}$ to the diameter and flatten the base curve by $0.6 \mathrm{~mm}$ to give clinical equivalent; e.g. Optimal $=8.6 / 14.2$; Large diameter $=9.2 / 15.4$. 